\title{
Heilige Kriege
}

Religiöse Begründungen militärischer Gewaltanwendung: Judentum, Christentum und Islam im Vergleich

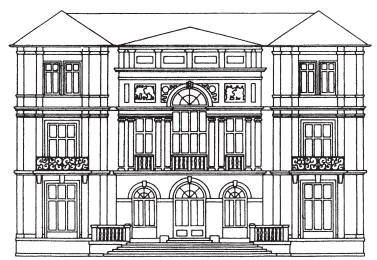




\section{Schriften des Historischen Kollegs}

Herausgegeben von Lothar Gall

Kolloquien

78

R. Oldenbourg Verlag München 2008 


\title{
Heilige Kriege
}

Religiöse Begründungen militärischer

Gewaltanwendung:

Judentum, Christentum und Islam im Vergleich

\author{
Herausgegeben von \\ Klaus Schreiner \\ unter Mitarbeit von \\ Elisabeth Müller-Luckner
}

R. Oldenbourg Verlag München 2008 


\author{
Schriften des Historischen Kollegs \\ herausgegeben von \\ Lothar Gall \\ in Verbindung mit \\ Johannes Fried, Hans-Werner Hahn, Manfred Hildermeier,
}

Martin Jehne, Claudia Märtl, Helmut Neuhaus, Friedrich Wilhelm Rothenpieler,

Luise Schorn-Schütte, Dietmar Willoweit und Andreas Wirsching

Seit 1983 tritt das Historische Kolleg alle drei Jahre durch die Vergabe seines mit $30000 €$ dotierten Preises, dessen Verleihung der Bundespräsident vornimmt, in besonderer Weise an die Öffentlichkeit.

Vom 7. bis 9. November 2007 fand anläßlich der neunten Verleihung des Preises des Historischen Kollegs an Gerhard A. Ritter ein Kolloquium zum Thema „Heilige Kriege. Religiöse Begründungen militärischer Gewaltanwendung: Judentum, Christentum und Islam im Vergleich“ als Kooperationsveranstaltung des Historischen Kollegs mit der Bayerischen Akademie der Wissenschaften in der Kaulbach-Villa statt. Gefördert wurde die Tagung durch die Fritz Thyssen Stiftung und die Bayerische Akademie der Wissenschaften; der vorliegende Band gedruckt mit Unterstützung der Fritz Thyssen Stiftung.

Das Historische Kolleg, gegründet im Jahr 1980, ist ein „Institute for Advanced Study“ der historisch orientierten Wissenschaften. Aktuell werden jedes Jahr fünf Stipendien (drei Forschungsund zwei Förderstipendien) für einen einjährigen Forschungsaufenthalt in München vergeben.

historischeskolleg.de

Kaulbachstraße 15, D-80539 München

Tel.: +49 (0)892866 3861

Fax: +49 (0)892866 3863

E-Mail: kontakt@historischeskolleg.de

Bibliografische Information der Deutschen Nationalbibliothek

Die Deutsche Nationalbibliothek verzeichnet diese Publikation in der Deutschen

Nationalbibliografie; detaillierte bibliografische Daten sind im Internet

über <http://dnb.d-nb.de> abrufbar.

(C) 2008 Oldenbourg Wissenschaftsverlag GmbH, München

Rosenheimer Straße 145, D-81671 München

Internet: oldenbourg.de

Das Werk einschließlich aller Abbildungen ist urheberrechtlich geschützt. Jede Verwertung außerhalb der Grenzen des Urheberrechtsgesetzes ist ohne Zustimmung des Verlages unzulässig und strafbar. Dies gilt insbesondere für Vervielfältigungen, Übersetzungen, Mikroverfilmungen und die Einspeicherung und Bearbeitung in elektronischen Systemen.

Gedruckt auf säurefreiem, alterungsbeständigem Papier (chlorfrei gebleicht)

Satz: Typodata GmbH, München

Druck: Memminger MedienCentrum, Memmingen

Bindung: Buchbinderei Klotz, Jettingen-Scheppach

ISBN 978-3-486-58848-4

\title{
Umschlag:
}

Ernst Barlach, Der heilige Krieg. Lithographie 1914. Beitrag für die Zeitschrift „Kriegszeit“

Nr. 17 vom 16. Dez. 1914, S. 3. Foto: Ernst Barlach Lizenzverwaltung, Ratzeburg. 